\title{
A semi-automated approach to generate 4D/5D BIM models for evaluating different offshore oil and gas platform decommissioning options
}

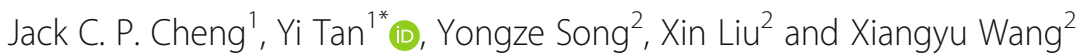

\begin{abstract}
Background: Offshore oil and gas platforms generally have a lifetime of 30 to 40 years, and platform decommissioning is a major issue because many of the existing offshore oil and gas platforms are reaching the end of their service life. There are many possible options for decommissioning offshore oil and gas platforms, and each decommissioning option can be implemented using different methods and technologies. Therefore, it is necessary to have a clear understanding and in-depth evaluation of each decommissioning option before commencing platform decommissioning. 4D and 5D building information modeling (BIM) has been commonly used in the building industry to analyze constructability and to evaluate different construction or demolition plans. However, application of BIM in the oil and gas industry, especially for the platform decommissioning process, is still limited.

Methods: This paper suggests and demonstrates the application of 4D and 5D BIM technology to simulate various methodologies to realize various selected offshore platform decommissioning options, thereby visualizing and evaluating different options, considering both the time and resources required for decommissioning process. One hundred and seventy-seven offshore platform decommissioning options are summarized in this paper. A new approach to create multiple 4D/5D BIM models in a semi-automated manner for evaluating various scenario options of OOGP decommissioning was proposed to reduce the model creation time as current way of 4D/5D BIM model creation for each OOGP decommissioning option is time consuming.

Results: In the proposed approach, an OOGP BIM model relationship database that contains possible 4D/5D BIM model relationships (i.e. schedules for different decommissioning methods) for different parts of an OOGP was generated. Different OOGP decommissioning options can be simulated and visualized with 4D/5D BIM models created by automatically matching schedules, resources, cost information and 3D BIM models. This paper also presents an illustrative example of the proposed approach, which simulates and evaluates two decommissioning options of a fixed jacket platform, namely Rig-to-Reef and Removal-to-Shore. As compared to the traditional approach of 4D/5D BIM model generation, the proposed semi-automated approach reduces the model generation time by $58.8 \%$ in the illustrative example.

(Continued on next page)
\end{abstract}

\footnotetext{
* Correspondence: ytanai@connect.ust.hk

'Department of Civil and Environmental Engineering, The Hong Kong

University of Science and Technology, Hong Kong, China

Full list of author information is available at the end of the article
} 
(Continued from previous page)

Conclusions: The proposed approach of semi-automated 4D/5D BIM model creation can help understand the implication of different decommissioning options as well as applied methods, detecting potential lifting clashes, and reducing 4D/5D BIM model creation time, leading to better planning and execution for the decommissioning of offshore oil and gas platforms. In addition, with the proposed semi-automated approach, the 4D/5D BIM model can be generated in a more efficient manner.

Keywords: 4D/5D BIM, Offshore platform decommissioning, Simulation, Visualization, What-if analysis

\section{Background}

Offshore oil and gas platforms (OOGPs) are large marine structure with facilities used to drill wells, to extract and process oil and natural gas, or to temporarily store products until they can be brought to shore for refining and marketing (See Fig. 1). Topsides, jacket, wells, and piles are the four main parts of a fixed platform. There are now around 1470 offshore oil rigs around the world based on the data from Statista (2015). OOGPs generally have a lifetime of 30-40 years, and the decommissioning of offshore platforms is a major issue in the oil and gas industry. Between 2010 and 2014, decommissioning cost in the Gulf of Mexico was approximately US \$9 billion, regularly exceeding US $\$ 1.5$ billion per year. Over the next 30 years, almost all the 470 offshore installations in the North Sea's UK Continental Shelf, will need to be

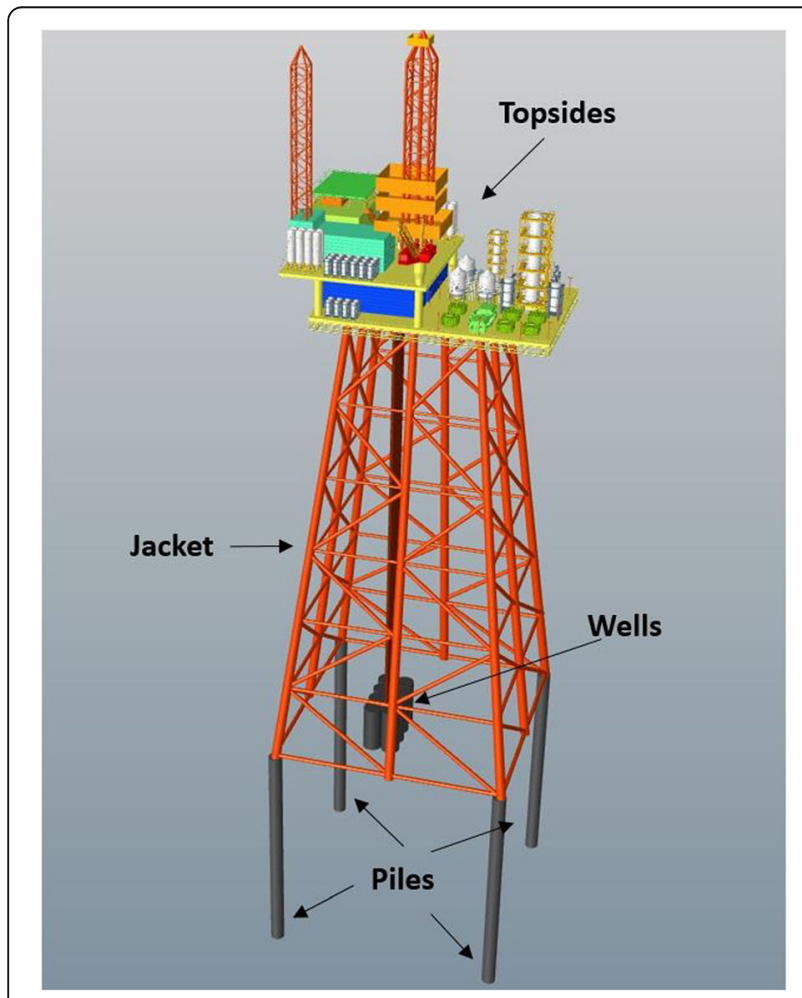

Fig. 1 An example of offshore oil and gas platform decommissioned, according to the UK Oil \& Gas Economic Report (2013). Twenty-seven offshore oil and gas platforms in southern California will be decommissioned by 2030 as the platforms will reach the end of their useful production lifetimes (Henrion et al. 2015). In Malaysia, the decommissioning activities for fixed offshore platforms are expected to rise significantly. There are approximately 300 oil platforms in Malaysia, many of which are approaching the end of their service life (Zawawi et al. 2012).

Due to the excessive OOGP decommissioning in the next decade and many possible options can be used to decommission OOGPs, studying potential decommissioning options is greatly needed. In addition, OOGPs are usually located at sea, which requires a more detailed and accurate program for decommissioning compared with the platforms on the land. Therefore, having a better understanding of the selected OOGP decommissioning option can ensure a smooth process in decommissioning, resulting in reduced idle working time and a better control of the project.

In the building industry, 4D building information modeling (BIM) has been used to simulate the construction or demolition plan. Using 4D BIM, different plans can be compared by visualizing the work sequences and duration of each task. Unreasonable logic in the sequence and task duration can be detected by professional project managers and engineers. Previous efforts have studied the application of 4D BIM for the monitoring of construction operations (Han \& Golparvar-Fard 2015), for reconstruction (Kacprzyk \& Kępa 2014), for construction progress measurement (Hu et al. 2008; Kim et al. 2013), for workspace conflict visualization (Moon et al. 2014) and for safety analysis (Hu et al. 2008; Zhou et al. 2013). However, 4D BIM application for OOGP decommissioning is understudied. The advantages of 4D BIM have been shown from the building industry, almost no studies talked about 4D BIM application in OOGP decommissioning. The differences in 4D BIM application between OOGP decommissioning and the building industry may be the reason. For example, the components and structures are different in the two industries, and multi-trucks can be used in building 
industry to carry the removed elements, while only one heavy lift vessel is usually used during OOGP decommissioning, requiring carefully planning.

In addition to the schedule, cost is another important concern for OOGP decommissioning. Equipment, materials, and labor are main resource costs in such projects. By incorporating resources, 4D BIM simulations turn into 5D BIM simulations, which can help understand resource utilization over time. 5D BIM has been studied and improved by a few research efforts ( $\mathrm{Lu}$ et al. 2016; Mitchell 2012; Scheer et al. 2014). By using 5D BIM models for OOGP decommissioning, timing and costs can be better planned and monitored to make sure projects are on track. The objective of this study is to develop a new approach to create multiple 4D/5D BIM models in a semi-automated manner for evaluating various scenario options of OOGP decommissioning.

This paper is organized as follows. Potential decommissioning options for OOGP will be first studied and summarized in Summarized Potential OOGP Decommissioning Options section. In 4D/5D BIM-based Framework for Evaluation of OOGP Decommissioning Options section, a proposed approach to create multiple 4D/5D BIM models in a semi-automated manner for evaluating OOGP decommissioning options will be proposed. An example will be presented in Illustrative Example section to illustrate the proposed approach, followed by the discussions and conclusions in Discussions and Conclusions section.

\section{Summarized potential OOGP decommissioning options}

Based on the systematic literature review, all potential OOGP decommissioning options are divided into three categories: reuse, recycling, and disposal. Usually, reuse has the top priority considering the sustainability as its energy consumption is relatively small compared to recycling (Zawawi et al. 2012) and more environmentally friendly than disposal. An OOGP can choose one decommissioning option for the whole structure. For example, the platform can be transferred to a Liquid Natural Gas (LNG) terminal or an offshore hotel (Zawawi et al. 2012). In addition, different decommissioning options can also be applied to the different parts of an OOGP. For example, the topsides can be removed to shore for recycling, the jacket can be toppled down for an artificial reef, and the pipeline can be left in place for disposal after clearance.

The choice of decommissioning options usually depends on the condition of OOGP. However, sometimes regional regulations may also impact the option decision. For example, in the North Sea, OSPAR Decision 98/3 requires any platform should be completely removed for further consideration, like reuse, if its jacket weight is less than 10,000 tons in air (1998). Therefore, the Rig-to-Reef program, which allows obsolete, nonproductive OOGP to be converted into artificial reefs to support marine habitats, has never been applied in the North Sea. On the contrary, many states in the United States like Texas, California, and Florida currently implement the Rig-to-Reef program for some of their platforms in the Gulf of Mexico, as well as the offshore southern California platforms in the near future.

For all possible decommissioning options, Bernstein et al. (2010) developed a tree by considering removal or partial removal, which only covers a small part of the potential options. In this paper, potential OOGP decommissioning options are further summarized by considering the platform as a whole or by sections, and filling each consideration with options that have ever been studied before, in both academic and industry fields (Fig. 2). When considering an OOGP as a whole, it can be left in-situ for LNG terminals, offshore hotel, or remove to land for reuse or recycle. Topsides, jacket, and other substructure can also have different decommissioning options when considering a platform by sections. For example, topsides can be removed to land for other reuse, while the jacket, in addition to being removed to land, can also be transferred into an artificial reef. Other substructures are usually left in the current place for natural degradation after cleaning. Two decommissioning options realized with different methodologies of a fixed jacket platform, namely Rigto-Reef and Removal-to-Shore, are evaluated by applying the 4D/5D BIM technology in this paper.

According to the summarized OOGP decommissioning options tree, there are 9 options when considering an OOGP as a whole, and a total of 168 potential options exist when considering an OOGP by sections. Therefore, many decommissioning options are available for an OOGP when it reaches its end of service life. In addition, each option can be realized by different methodologies. For example, when topsides is considered to be removed to land, it can be removed as a whole in a single lift by using huge lift vessel, or it can be removed using the reverse installation method, which removes the topsides in modules following the reverse process to its installation. As the working environment of OOGP decommissioning is more demanding compared to the related work onshore, it is important to evaluate different methodologies for the selected decommissioning option. Since 177 possible OOGP decommissioning options are available, the traditional 4D/5D BIM model creation method, which is usually manually conducted, is time consuming. Therefore, in this study, a semi-automated 4D/5D BIM model creation approach was proposed to reduce the model creation time. 


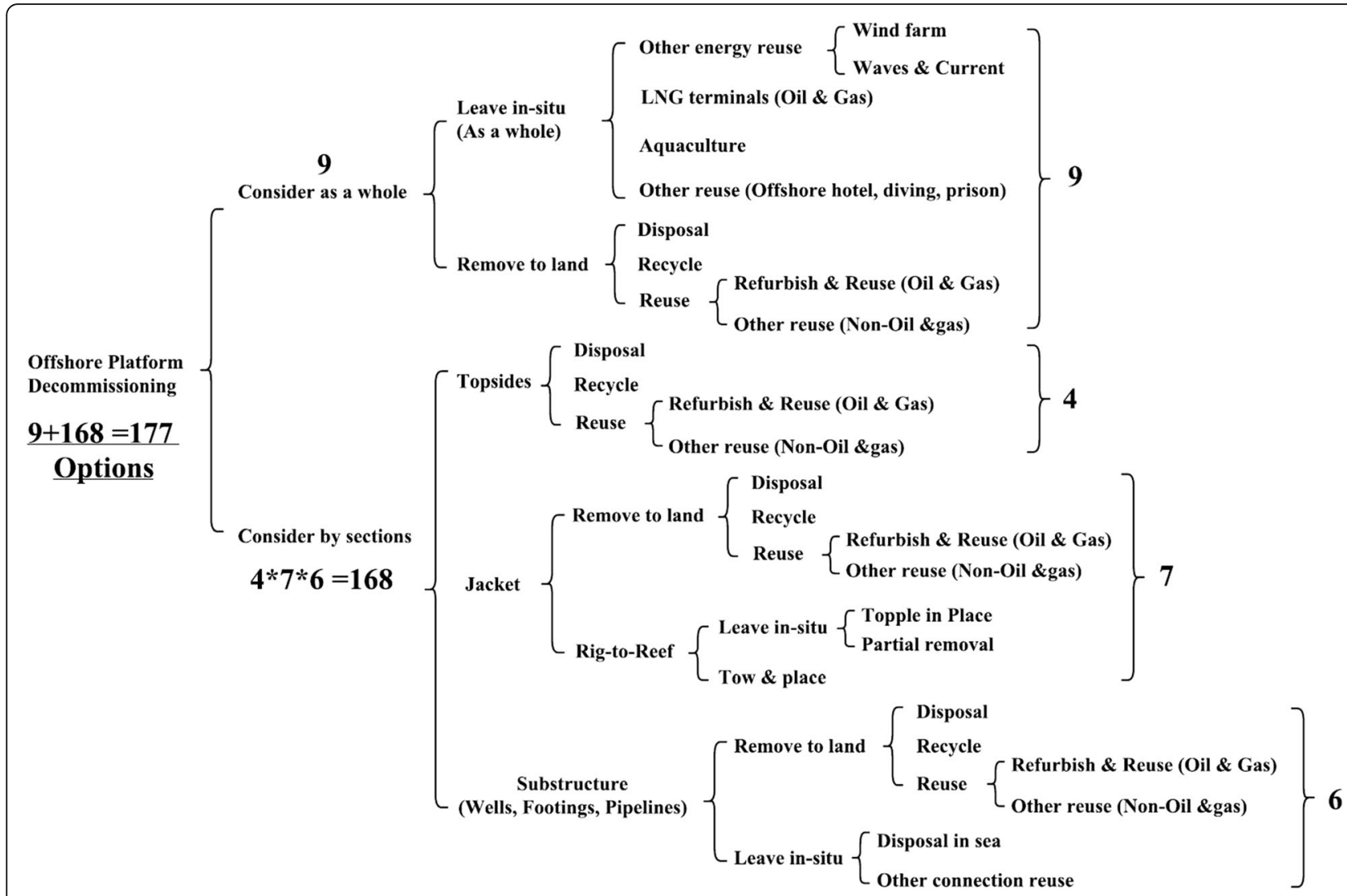

Fig. 2 Potential options for OOGP decommissioning

\section{Methods}

In order to evaluate OOGP decommissioning options in an efficient way, a new approach of semi-automated 4D/ 5D BIM model creation (Fig. 3) is proposed to conduct process simulations and comparisons among different decommissioning options. What-if analysis conducted by the proposed approach provides a good reference for decision making according to decommissioning sequence simulation, resource utilization visualization, and time and cost monitoring. In the proposed approach, the object-task (O-T) relationships (i.e. schedules) of OOGP decommissioning options are first created. Then the schedule is connected to the external resource database to create object-task-cost (O-T-C) relationships, which is the integration of schedule, resources, and cost information for the OOGP decommissioning options. Based on the created O-T and O-T-C relationships, a database of OOG decommissioning option relationships among related decommissioning tasks, resources, cost information, and 3D BIM models for different OOGP parts such as topsides $(\mathrm{T})$, jacket $(\mathrm{J})$, and substructure $(\mathrm{S})$ can be generated. With the generated database, relationships of different decommissioning options for an OOGP can be obtained. Based on the obtained relationships, 3D BIM models, schedules, resources, and cost information can then be automatically matched by building matching rule between them. Based on the created 4D/5D BIM models for OOGP decommissioning options, decommissioning processes and resource utilization can be simulated and visualized efficiently. More details of the proposed approach are introduced in the following sections.

\section{D BIM model relationship creation (object-task)}

In the proposed approach, the first step is to create a 4D BIM model relationship for the topsides, jacket, substructure, and other parts of an OOGP. The 4D BIM model relationship consists of 3D model names and task names. In the building industry, 4D BIM has been commonly used to simulate construction or demolition plans by visualizing the sequences and durations of activities. Usually, 3D objects in the BIM model are assigned to the related tasks in the schedule to create a 4D BIM model.

In an OOGP decommissioning project, two main stages are included: the preparation stage and the lift stage. During the preparation stage, functional modules on the platform need to be separated, emptied, cleaned and fastened. In the lift stage, the prepared modules are lifted by HLV and then shipped to land for further 


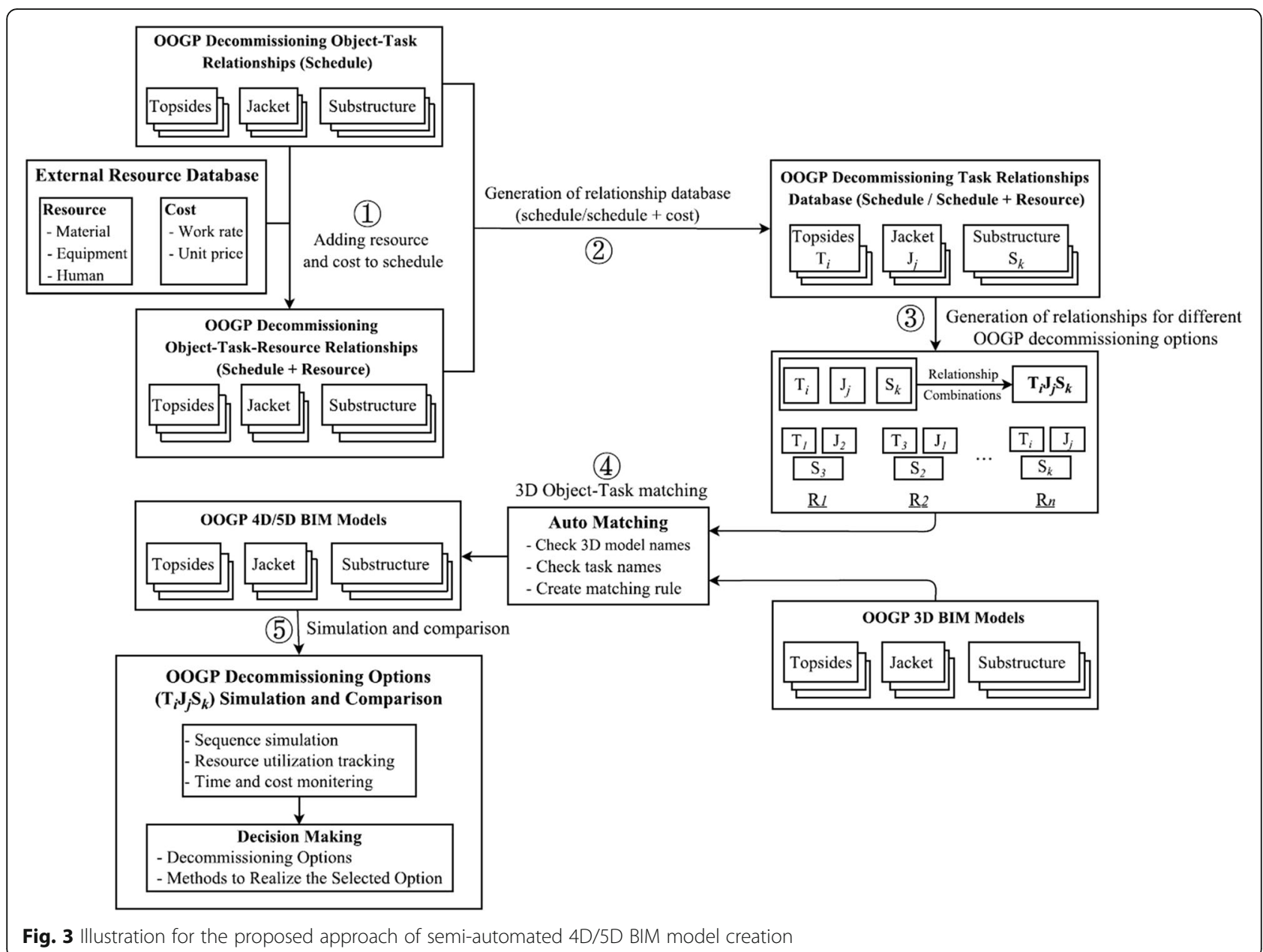

considerations. The total estimated duration for each methodology in the selected decommissioning option can be obtained by the following equation:

Duration $=\frac{\text { Modules Volume }\left(m^{3}\right)}{\text { Preparation Work Rate }\left(m^{3} / \text { day }\right)}+\frac{\text { Total Lift Distance }(m)}{\text { Lift Speed }(m / \text { day })}$

where the modules' volume can be obtained directly from 3D BIM models, preparation work rate can be obtained from a subcontractor who takes charge of the preparation work, the lift path were defined by Tan et al. (2017) on the work of lift planning and the lift speed is from working parameters of the crane on the HLV.

\section{D BIM model relationship creation (object-task-cost)}

Based on the created 4D BIM model relationships, resources including material, equipment, and human were added to related schedules. In addition, resource cost information such as human work rate and material unit price was also included. With the added resources and cost information, 5D BIM model relationships for the OOGP decommissioning options were developed. When adding cost to schedules, two ways can usually be used. One is to assign estimated cost directly to a related task, the other is to assign resources like equipment, material, and labor to a related activity. Before resource assignment, the work rate and unit price of each resource are defined. For example, during preparation stage of OOGP decommissioning, workers are needed to empty and clean all the pipes and tanks on the platform. Therefore, labor named cleaner is defined. Then work rate (person per day) and unit price (dollars per person per day) are added to the cleaner. Finally, according to resource plan, cleaners are assigned, for instance, as pipe cleaning.

In this study, resources are assigned to create a $5 \mathrm{D}$ BIM model considering that not only cost of the project can be visualized over time, but also resource utilization can be tracked during 5D BIM simulation. This provides a good reference for decommissioning program development. In the next section, the created 4D and 5D BIM models will be integrated to generate a database that can 
used to form a decommissioning 4D/5D BIM model for an OOGP.

\section{OOGP 4D/5D BIM model relationship database for decommissioning options}

With the created 4D and 5D BIM model relationships for different OOGP parts such as topsides, jacket, and substructure, a 4D/5D BIM relationship database can be generated. A fixed platform was used as an example in this study, and four parts: topsides, jacket, substructure (wells), and piles are included in a fixed platform. Piles are usually left in place for naturally degrading, therefore, different 4D/5D BIM model relationships for topsides $\left(\mathrm{T}_{i}\right)$, jacket $\left(\mathrm{J}_{j}\right)$, and substructure $\left(\mathrm{S}_{k}\right)$ of the fixed platform were created in this study. With the created 4D/5D BIM model relationships $\left(\mathrm{T}_{i}, \mathrm{~J}_{j}, \mathrm{~S}_{k}\right)$, different OOGP decommissioning option relationships (schedules / schedules, resources, and cost information) can be formulated by combining $\mathrm{T}_{i}, \mathrm{~J}_{j}$, and $\mathrm{S}_{k}$.

$4 \mathrm{D} / 5 \mathrm{D}$ BIM model relationship is commonly represented in file formats such as comma-separated values (CSV), Microsoft Project Exchange File Format (MPX), and Extensible Markup Language (XML). Therefore, the created 4D/5D BIM model relationship database usually contains CSV, MPX, or XML files $\left(\mathrm{T}_{i}, \mathrm{~J}_{j}, \mathrm{~S}_{k}\right)$ that store decommissioning schedules, resources, and cost information for different OOGP sections. In order to generate decommissioning options for OOGPs efficiently, methodology is developed to combine the relationship files from the database automatically. The results of the combinations are CSV, MPX, or XML files that contain schedules, resources, and cost information of different decommissioning options for complete OOGPs. To illustrate the 4D/5D BIM model relationship combination, an example using XML file as the representation of the relationship is used (See Fig. 4). In the example, Document Object Model (DOM) was used to parse each XML file and combine them to form different OOGP decommissioning options into XML files. As compared to the traditional approach, using the developed combination methodology to generate decommissioning options for OOGPs can significantly improve the efficiency.

\section{D BIM object-task auto assignment}

Assigning 3D BIM objects to related tasks is one of the main steps when creating 4D/5D BIM models. Traditional method of object-task assignment is manually conducted, which usually costs much time especially when the project is big and complex. Therefore, in the proposed approach, the object-task assignment was improved and automated by creating matching rules between 3D objects and related tasks in the schedules. Matching rules can be divided into code-based and linguistic-based matching rules. As for code-based matching rules, 3D objects and tasks in the schedules are usually encoded with serial numbers. Each serial number contains necessary information to identify each task and 3D object. The digits in each serial number can be used to represent information like project, building level, room, material category, and object number. The encoding process can be time consuming, but codebased matching rules are usually accurate and efficient, especially for mega complex projects. The other matching rule is linguistic-based, which matches $3 \mathrm{D}$ objects and related tasks by their names. Similar names of 3D objects and tasks are usually recognized and matched with each other. Since the 3D objects and tasks already have their names before importing to simulation applications, the matching rule creating time of linguistic-based methodology is less compared to that of code-based methodology. However, when the project getting complex, the accuracy of linguistic-based matching rule will be impacted. Extra time has to be spent on the naming of the 3D objects and related tasks. Since this paper focuses on OOGP decommissioning, the objects on platform are unique, linguistic-based matching rule is

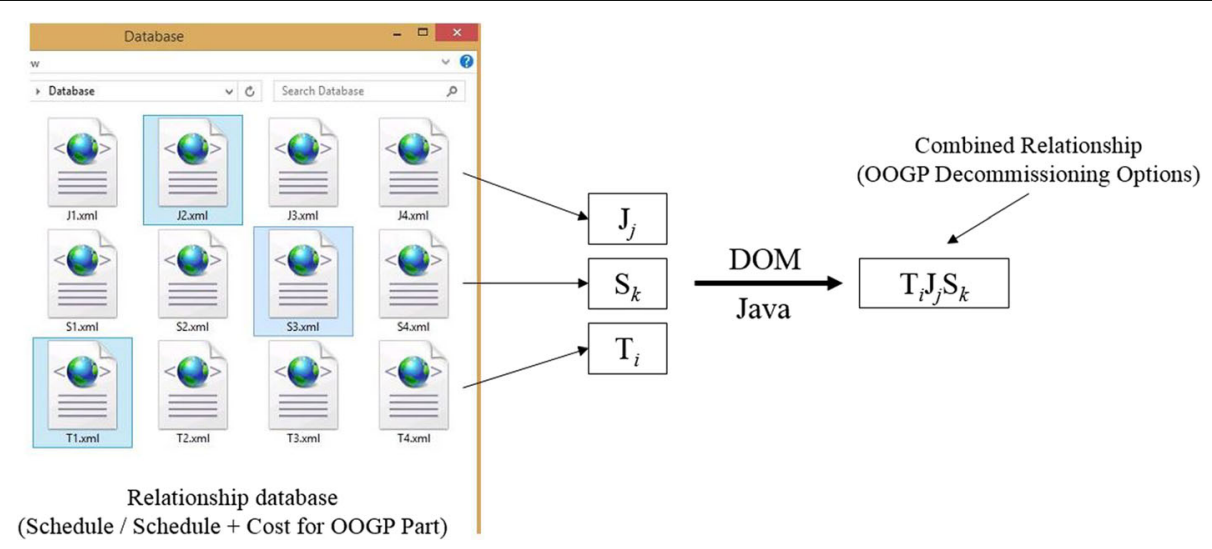

Fig. 4 Illustration of 4D/5D BIM model relationship combination 
used to conduct object-task assignment when creating 4D/5D BIM models for OOGP decommissioning.

In order to guarantee that 3D BIM objects match tasks accurately, the names of the objects and tasks require to be briefly checked. As 3D BIM object names are usually the same as the real names of the objects on OOGP, task names are usually adjusted. Some 3D BIM objects may also be used for multiple tasks. For example, before the disassembly of topsides, all modules are required to be cleaned and emptied before being removed and lifted by heavy lift vessel. Therefore, in order to assign the 3D BIM modules to both tasks, the relation in the matching rule is set as many-to-many. With the created matching rule between 3D BIM objects and decommissioning tasks, 4D/5D BIM models for different OOGP decommissioning options with different methodologies can be generated in a quick manner, saving much time for the model generation. Finally, different decommissioning options can be visualized and evaluated.

\section{Simulation and comparison}

Based on the generated 4D/5D BIM models $\left(\mathrm{T}_{i}+\mathrm{J}_{j}+\mathrm{S}_{k}\right)$, different methodologies for the selected OOGP decommissioning option can be simulated and compared efficiently. Any combination of $\mathrm{T}_{i}, \mathrm{~J}_{j}$, and $\mathrm{S}_{k}$ can form one OOGP decommissioning option. For example, topsides is usually removed to shore for further considerations like recycle, reuse or disposal. To realize the removal of topsides from an OOGP, reverse installation $\left(\mathrm{T}_{1}\right)$, single lift $\left(\mathrm{T}_{2}\right)$, and offshore deconstruction $\left(\mathrm{T}_{3}\right)$ can be used. As for the jacket, it can be toppled in current place for reef $\left(\mathrm{J}_{1}\right)$ or remove to shore for further considerations. Single lift $\left(\mathrm{J}_{2}\right)$ and offshore deconstruction $\left(\mathrm{J}_{3}\right)$ can be used for jacket removal. Therefore, when just considering topsides and jacket of an OOGP in the example, two OOGP decommissioning options with different methods can be obtained. One is to remove topsides to shore and turn jacket into a reef, for this decommissioning option, 3 methods combinations: $\mathrm{T}_{1}+\mathrm{J}_{1}, \mathrm{~T}_{2}+\mathrm{J}_{1}, \mathrm{~T}_{3}+\mathrm{J}_{1}$ can be formed. Another decommissioning option is to remove both topsides and jacket to shore. For this option, 6 method combinations: $\mathrm{T}_{1}+\mathrm{J}_{2}, \mathrm{~T}_{2}+\mathrm{J}_{2}, \mathrm{~T}_{3}+\mathrm{J}_{2}, \mathrm{~T}_{1}+\mathrm{J}_{3}, \mathrm{~T}_{2}$ $+J_{3}$, and $T_{3}+J_{3}$ can be formed. Totally 9 method combinations that can realize two OOGP decommissioning options can be evaluated based on the created $4 \mathrm{D} / 5 \mathrm{D}$ BIM model database given that all $\mathrm{T}_{i}$ and $\mathrm{J}_{j}$ are available. In addition, the $4 \mathrm{D} / 5 \mathrm{D}$ BIM model generation time can be reduced by using the proposed semi-automated approach. Traditional approach of 4D/5D BIM model generation is usually to create an integrated model for each mentioned method combination $\left(T_{i}+J_{j}\right)$ where the model generation process is continuous. $T_{i}$ and $J_{j}$ have to be created multiple times as they are included in several combinations. However, with the proposed semi- automated approach, $T_{i}$ and $\mathrm{J}_{\mathrm{j}}$ can be created separately only once and then combined for the evaluation and analysis several times by using the developed combination methodology.

Usually, meetings are set up for a project manager, stakeholders of platform, engineers, and operator of HLV to go through all what-if scenarios, and discussions are conducted and options on the decommissioning program are proposed. With the generated 4D BIM models, the OOGP decommissioning processes that reflect the changes of 3D BIM models can be visualized and evaluated. Unreasonable decommissioning sequences and durations of tasks can be identified during the 4D BIM simulation. With the created 5D BIM models, not only the decommissioning processes and duration can be visualized, but also the resources utilization and cost changes across time can be visualized and monitored. Based on 5D BIM simulation, resources allocation and cash flow can be better planned. During the 4D/5D BIM simulations, different meeting participants will focus on different parts of the OOGP decommissioning project, providing professional advices. The visualization of OOGP decommissioning processes, resources utilization, and cost changes can support the decision making on OOGP decommissioning option selection. Finally, the OOGP decommissioning program can be developed and used as a benchmark to monitor and control the project.

\section{Illustrative example OOGP BIM model}

In order to illustrate the proposed approach, an example is used. The model used in the example is a fixed platform with steel jacket piled in the seabed, supporting a deck containing about 30 modules including production facilities, drilling rigs, crew quarters, and other modules (Fig. 5). The model was originally represented in 3dsMax, it was exported to DWF format from Autodesk 3dsMax, and then imported in Autodesk Revit. As the OOGP model was represented as a surface model, which represents objects with different surfaces, related surfaces that belong to one module were grouped together. The grouped model was then exported to Industry Foundation Classes (IFC) file format and imported into the simulation application, namely Synchro Pro, to create 4D/5D BIM models for evaluating different decommissioning options.

\section{OOGP decommissioning options and methodologies}

Rig-to-Reef and Removal-to-Shore decommissioning options were selected for the prepared OOGP model to validate the proposed approach. Different disassembly methods can be used to realize the two selected 


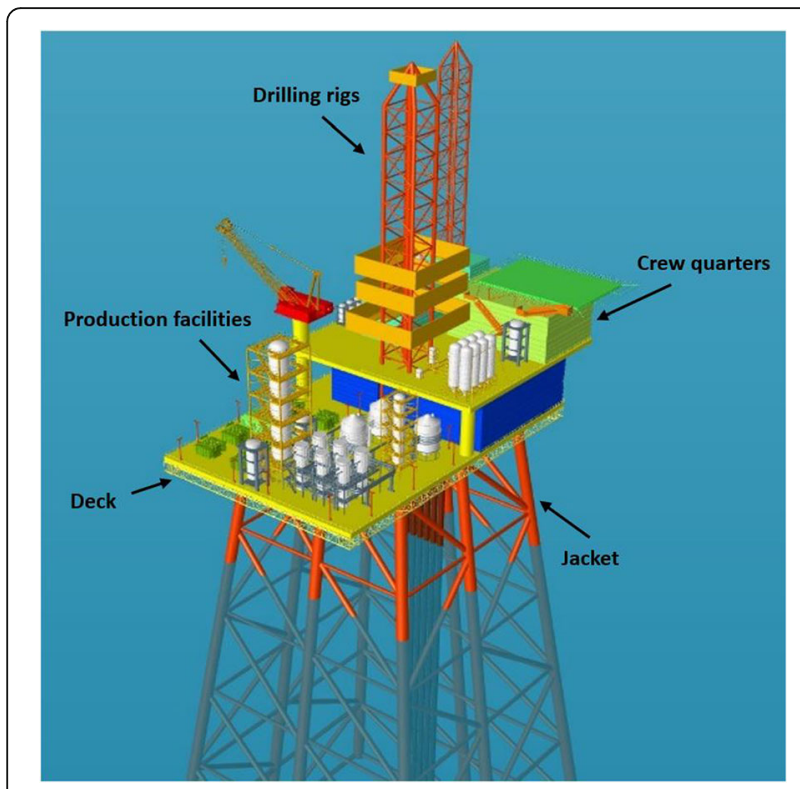

Fig. 5 Overview of the OOGP BIM model

decommissioning options. Furthermore, for both selected decommissioning options, topsides was removed to land for further consideration. Topsides removal can be realized by using reverse installation and single lift methods. While for the steel jacket, offshore deconstruction, single lift, and topple in place for reef can be applied. Since the substructure (i.e. drilling well) and piles will be left in current place for naturally degraded, therefore they will not be discussed in this study. Table 1 summarizes the two decommissioning options and illustration of each method.

As presented in Table 1, there are two methods for Rig-to-Reef option and four methods for Removal-toShore option, respectively. For Rig-to-Reef option, the two method combinations are $\mathrm{T} 1+\mathrm{J} 1$ and $\mathrm{T} 2+\mathrm{J} 1$. For Removal-to-Shore option, the four method combinations were: $\mathrm{T} 1+\mathrm{J} 2, \mathrm{~T} 1+\mathrm{J} 3, \mathrm{~T} 2+\mathrm{J} 2$, and $\mathrm{T} 2+\mathrm{J} 3$. Schedule for each method combination was developed in the schedule software namely Primavera and Fig. 6 shows an example of $\mathrm{T} 1+\mathrm{J} 2$ for the Removal-to-Shore option.

\section{Resources creation}

As mentioned in 5D BIM Model Relationship Creation (Object-Task-Cost) section, resource assignment is selected in this study to create 5D BIM models of OOGP decommissioning. A few required resources were defined firstly. According to OOGP decommissioning activities, the defined resources were divided into three categories: equipment, materials, and labor. For most of removal methods mentioned in this example includes preparation stage and lifting stage. During the preparation stage, tools or equipment are required to cut or separate connections between different structures, chemical materials are required to clean the emptied pipes and tanks, and all these tasks are conducted by different classes of workers. In the lifting stage, the most important equipment is heavy lift vessel (HLV). Detailed resources definitions are listed in Table 2.

\section{OOGP decommissioning scenarios and analysis}

The 3D OOGP BIM model and the combined relationships (schedules of the decommissioning options) were imported into Synchro Pro (2016), and the required resources with cost were then defined. 4D and 5D BIM models of decommissioning scenarios were created by automatically matching 3D BIM models to the related tasks in the schedule and by assigning resources to activities, respectively. The two selected OOGP decommissioning options: Rig-to-reef and Removal-to-shore can be formed by integrating different 4D/5D BIM models (i.e. different decommissioning methods) of topsides $\left(\mathrm{T}_{i}\right)$ and jacket $\left(\mathrm{J}_{j}\right)$, totally 6 method combinations were generated for decommissioning simulation (Table 1). Then, with the help of the Play function in the Synchro Pro, each option and different methodologies can be simulated and visualized.

\section{Results}

Figure 7 shows some of the OOGP decommissioning options and methods simulation. Decommissioning methods of T1, T2, J1, and J2 are demonstrated respectively in the picture. In addition to visualizing the sequences of each methodology, the exact time for the different phases, for example, at what time the living

Table 1 OOGP decommissioning options and the methods

\begin{tabular}{lllll}
\hline & RIG-TO-REEF & & REMOVAL-TO-SHORE & \\
\hline Topsides & T1: & T2: & T1: & T2: \\
& Reverse Installation & Single Lift & Reverse Installation & Single Lift \\
Jacket & & J2: & J3: \\
& J1: & & Single Lift & Offshore Deconstruction \\
\hline
\end{tabular}

Reverse Installation (T1): Remove the platform following the reverse process of installation

Single Lift (T2 or J2): Remove the topsides or jacket by only one lift with the help of huge lift vessel

Offshore Deconstruction (J3): Cut the jacket into sections with ROV and lift onto barge before shipping to land

Topple in Place for Reef (J1): Topple the whole jacket in the current place for the artificial reef program 


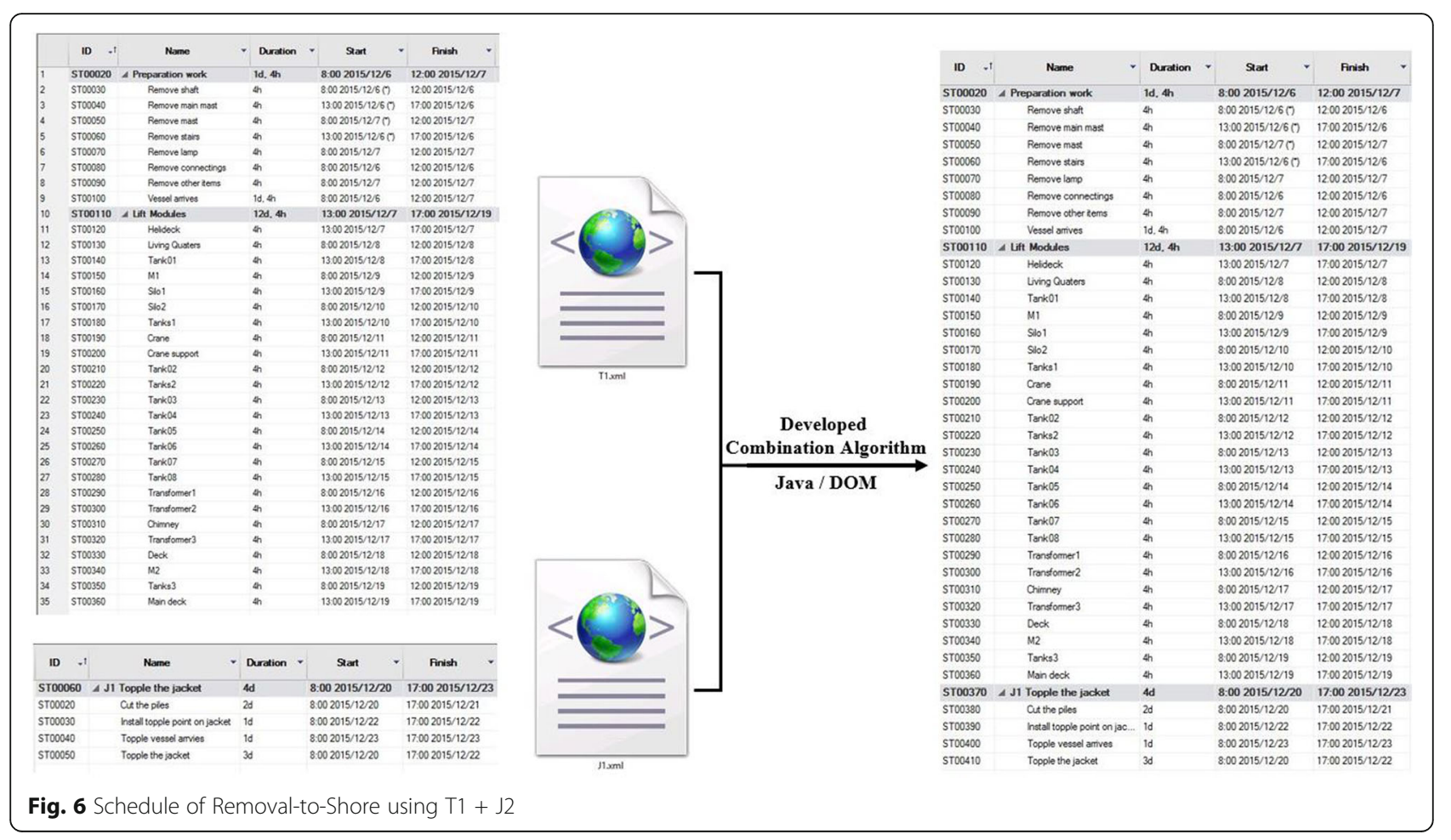

quarter was under lifting can also be visualized. By visualizing the duration of each decommissioning activity, engineers can detect potential unreasonable time arrangement, such as idle time. Duration of OOGP decommissioning activities was then modified. The finalized durations for Rig-to-Reef and Removal-toShore options using different disassembly methods are summarized in Table 3.

By assigning resources to disassembly activities that have been rescheduled, the cost of the decommissioning project can also be visualized over time (Fig. 8). Such cost visualization can guarantee that the cost is under a better control for the OOGP decommissioning program development.

In addition to the general cost visualization for each removal method, the detailed information for each method can also be obtained. The detailed cost and duration information for topsides removal methods: $\mathrm{T} 1$ and $\mathrm{T} 2$ are presented as an example (Fig. 9).

As compared to the traditional approach of $4 \mathrm{D} / 5 \mathrm{D}$ BIM model generation, the proposed semi-automated approach reduces the model generation time. As shown in Table 4, the total model generation time by the traditional approach is $51 \mathrm{~h}$, while the proposed

Table 2 Detailed resource information

\begin{tabular}{lll}
\hline Resource Category & Name & Notes \\
\hline Equipment & Cutting Tools & To separate connections between modules \\
& Heavy Lift Vessel (HLV) & To Lift modules and structures from platform to vessel and then ship them to land \\
Materials & Chemicals (Cleaning) & To clean empty pipes and tanks before lifting \\
& Materials (Fastening) & To fasten and strengthen modules before lifting \\
Labor & Cleaner & Use chemical materials to clean and empty pipes, etc. \\
& Separator & Use tools to cut connections between modules \\
& Fastener & Use materials and equipment to fasten modules \\
& Lifting Assistant & Help during lifting \\
& Crane Operator & Operate crane on HLV \\
& Project manager & Take charge of the whole decommissioning project \\
& Other Engineers & Calculate lifting points, plan the lifting path, etc. \\
\hline
\end{tabular}




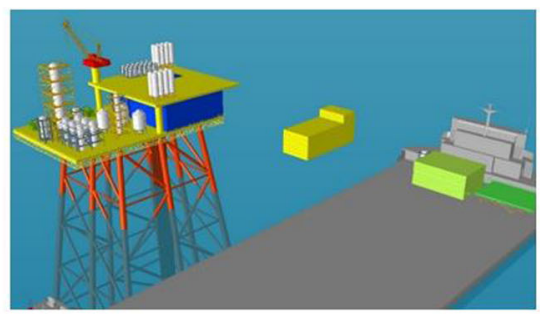

(a) Remove the modules from the platform

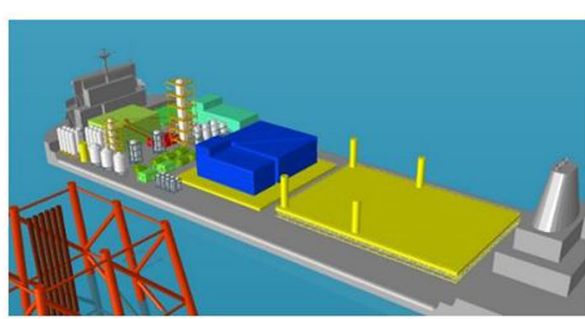

(b) Put all the modules on the vessel and ship to shore

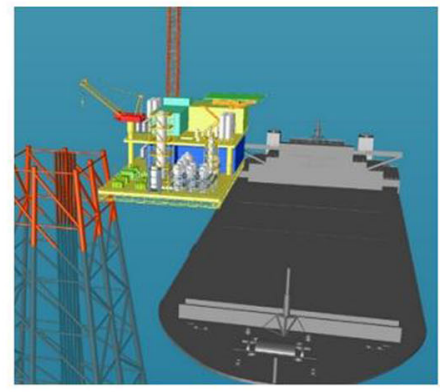

(c) Remove the topsides with single lift

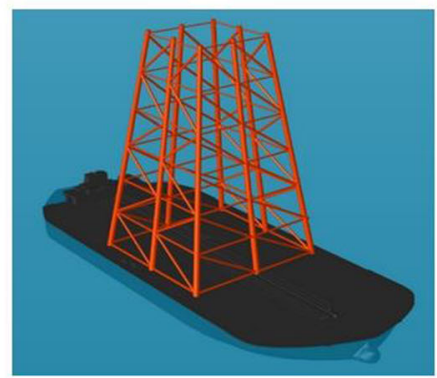

(e) Remove jacket with single lift

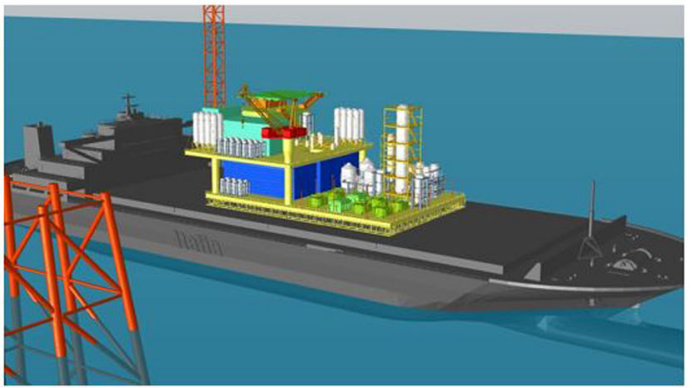

(d) Put the topsides on the vessel and ship to shore

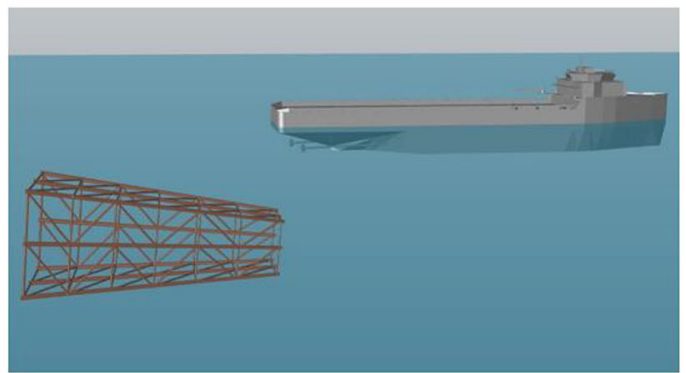

(f) Tilt and leave the jacket on site as reef

Fig. 7 OOGP decommissioning options and methods simulation demonstration

semi-automated approach only uses $21 \mathrm{~h}$. The model generation time is reduced by $58.8 \%$ in the illustrative example.

\section{Discussions and conclusions}

This paper presents and demonstrates a new approach to create multiple $4 \mathrm{D} / 5 \mathrm{D}$ BIM models in a semiautomated manner for evaluating various scenario options of OOGP decommissioning. An OOGP 4D/5D BIM model relationship database that contains different

Table 3 Estimate duration for each option with different methods

\begin{tabular}{lll}
\hline Option & Method & Estimated Duration (Days) \\
\hline Rig-to-Reef & $\mathrm{T} 1+\mathrm{J} 1$ & 18 \\
& $\mathrm{~T} 2+\mathrm{J} 1$ & 10 \\
Removal-to-Shore & $\mathrm{T} 1+\mathrm{J} 2$ & 19 \\
& $\mathrm{~T} 1+\mathrm{J} 3$ & 22 \\
$\mathrm{~T} 2+\mathrm{J} 2$ & 11 \\
& $\mathrm{~T} 2+\mathrm{J} 3$ & 14 \\
\hline
\end{tabular}

decommissioning schedules (or schedules and resource) for OOGP parts such as topsides, jacket, and substructure. 3D BIM models and combined 4D/5D BIM model relationships can be automatically matched to generate 4D/5D BIM models for OOGP decommissioning options. With the created 4D/5D BIM models, Rig-to-Reef and Removal-to-Shore options and their methods can be clearly visualized, and the model creation time was reduced. The visualization provides a good reference for project managers to plan and execute OOGP decommissioning, and potentially unreasonable working sequences and lengthy activity durations can be detected and resolved. 5D BIM models of OOGP decommissioning can visualize and track resource utilization, helping the development of detailed resource plans. In addition, 5D BIM models can help monitor the cost of an OOGP decommissioning project.

According to results of the illustrative example, the proposed new approach of semi-automated 4D/5D BIM model creation for OOGP decommissioning can 


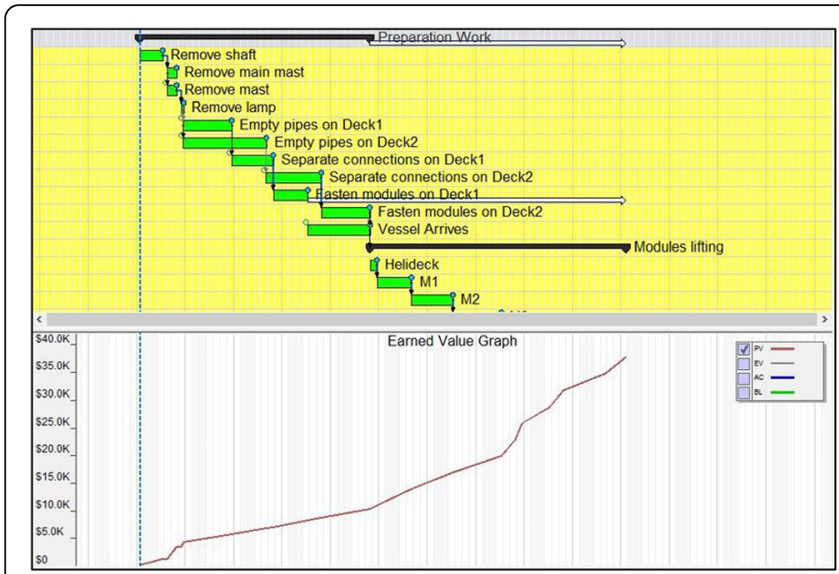

(a)

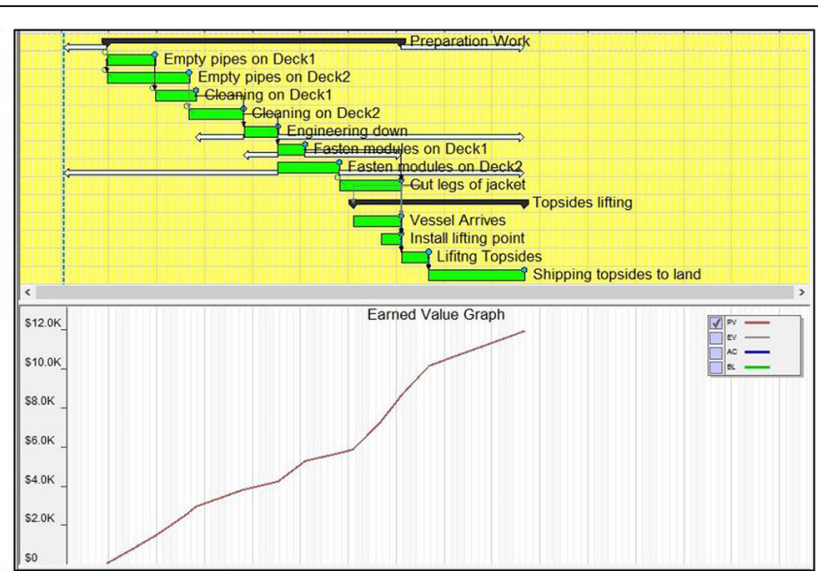

(b)

Fig. 8 Illustration of cost control on two topsides removal methods: a Reverse installation. b Single lift

facilitate a better understanding of different disassembly plans for offshore platforms, including the lifting sequence, resource utilization, and duration during decommissioning. Potentially unreasonable sequences in the decommissioning activities and unnecessary downtime can be detected during 4D/5D BIM simulations and comparisons. In addition, according to the finalized working plan, the resource utilization at different stages can be used as a reference for equipment, material and labor plan, which reduces the possibility of work shutdown as the offshore traffic is more demanding compared to that onshore. The simulation results can also be used as a benchmark for the decommissioning project control and as training materials for workers on the platform. Finally, the illustrative case shows that using the proposed semi- automated approach can reduce the 4D/5D BIM model generation time by $58.8 \%$ compared with the traditional method.

However, the proposed approach also has some limitations. As mentioned in the illustrative example, the data schema for representing OOGP in BIM is still lacking. Currently, IFC, which is the main neutral file format for data exchange among AEC/facility management software, does not include OOGP entities such as integrated function modules, pipes, valves, and other elements on offshore platform. Using building elements to represent OOGP elements creates many problems (Cheng et al. 2016). The BIM model for $4 \mathrm{D} / 5 \mathrm{D}$ simulations used in the illustrative example was not represented with defined IFC entities such as ifcwall, ifcdoor, and ifcwindow, they were all represented

\begin{tabular}{|l|r|r|r|r|}
\hline OOGP Decommissioning Activities & \multicolumn{1}{l}{ Start } & \multicolumn{1}{l}{ Finish } & Duration & Budgeted Total \\
\hline Preparation Work & $1 / 1 / 2016$ & $1 / 14 / 2016$ & 14 & $\$ 10,470$ \\
\hline Remove shaft & $1 / 1 / 2016$ & $1 / 2 / 2016$ & 2 & $\$ 1,400$ \\
\hline Remove main mast & $1 / 2 / 2016$ & $1 / 3 / 2016$ & 2 & $\$ 800$ \\
\hline Remove mast & $1 / 2 / 2016$ & $1 / 3 / 2016$ & 2 & $\$ 1,400$ \\
\hline Remove lamp & $1 / 4 / 2016$ & $1 / 4 / 2016$ & 1 & $\$ 800$ \\
\hline Empty pipes on Deck1 & $1 / 4 / 2016$ & $1 / 6 / 2016$ & 3 & $\$ 900$ \\
\hline Empty pipes on Deck2 & $1 / 4 / 2016$ & $1 / 8 / 2016$ & 5 & $\$ 950$ \\
\hline Separate connections on Deck1 & $1 / 7 / 2016$ & $1 / 9 / 2016$ & 3 & $\$ 800$ \\
\hline Separate connections on Deck2 & $1 / 9 / 2016$ & $1 / 11 / 2016$ & 3 & $\$ 850$ \\
\hline Fasten modules on Deck1 & $1 / 10 / 2016$ & $1 / 11 / 2016$ & 2 & $\$ 720$ \\
\hline Fasten modules on Deck2 & $1 / 12 / 2016$ & $1 / 14 / 2016$ & 3 & $\$ 950$ \\
\hline Vessel Arrives & $1 / 9 / 2016$ & $1 / 14 / 2016$ & 6 & $\$ 900$ \\
\hline Modules lifting & $1 / 15 / 2016$ & $1 / 16 / 2016$ & 2 & $\$ 27,400$ \\
\hline Helideck & $1 / 15 / 2016$ & $1 / 15 / 2016$ & 1 & $\$ 580$ \\
\hline M1 & $1 / 15 / 2016$ & $1 / 15 / 2016$ & 1 & $\$ 2,980$ \\
\hline M2 & $1 / 15 / 2016$ & $1 / 15 / 2016$ & 1 & $\$ 2,980$ \\
\hline M3 & $1 / 15 / 2016$ & $1 / 15 / 2016$ & 1 & $\$ 2,980$ \\
\hline Deck1 & $1 / 15 / 2016$ & $1 / 15 / 2016$ & 1 & $\$ 2,980$ \\
\hline M4 & $1 / 16 / 2016$ & $1 / 16 / 2016$ & 1 & $\$ 2,980$ \\
\hline M5 & $1 / 16 / 2016$ & $1 / 16 / 2016$ & 1 & $\$ 2,980$ \\
\hline M6 & $1 / 16 / 2016$ & $1 / 16 / 2016$ & 1 & $\$ 2,980$ \\
\hline M7 & $1 / 16 / 2016$ & $1 / 16 / 2016$ & 1 & $\$ 2,980$ \\
\hline Main Deck & $1 / 16 / 2016$ & $1 / 16 / 2016$ & 1 & $\$ 2,980$ \\
\hline
\end{tabular}

\begin{tabular}{|c|c|c|c|c|}
\hline OOGP Decommissioning Activities & Start & Finish & Duration & Budgeted Total \\
\hline Preparation Work & $1 / 1 / 2016$ & $1 / 7 / 2016$ & 7 & $\$ 5,370$ \\
\hline Empty pipes on Deck1 & $1 / 1 / 2016$ & $1 / 2 / 2016$ & 2 & $\$ 900$ \\
\hline Empty pipes on Deck2 & $1 / 1 / 2016$ & $1 / 2 / 2016$ & 2 & $\$ 950$ \\
\hline Fasten modules on Deck1 & $1 / 3 / 2016$ & $1 / 4 / 2016$ & 2 & $\$ 720$ \\
\hline Fasten modules on Deck2 & $1 / 3 / 2016$ & $1 / 4 / 2016$ & 2 & $\$ 950$ \\
\hline Separate Topsides & $1 / 5 / 2016$ & $1 / 7 / 2016$ & 3 & $\$ 950$ \\
\hline Vessel Arrives & $1 / 2 / 2016$ & $1 / 7 / 2016$ & 6 & $\$ 900$ \\
\hline Topsides lifting & $1 / 8 / 2016$ & $1 / 8 / 2016$ & 1 & $\$ 28,000$ \\
\hline Topsides Lift & $1 / 8 / 2016$ & $1 / 8 / 2016$ & 1 & $\$ 28,000$ \\
\hline
\end{tabular}

T2: Remove the topsides by only one lift with the help of huge lift vessel

Fig. 9 Illustration of detailed cost and duration information of T1 and T2 
Table 4 Comparison of 4D/5D BIM model generation time between traditional and proposed approaches

\begin{tabular}{|c|c|c|c|c|}
\hline \multirow[b]{2}{*}{ Options } & \multicolumn{2}{|c|}{ Traditional Approach } & \multicolumn{2}{|c|}{ Proposed Semi-automated Approach } \\
\hline & Methods & $\begin{array}{c}\text { 4D/5D BIM model } \\
\text { creation time (Hours) }\end{array}$ & Methods & $\begin{array}{l}\text { 4D/5D BIM model } \\
\text { creation time (Hours) }\end{array}$ \\
\hline \multirow{2}{*}{ Rig-to-Reef } & $\mathrm{T} 1+\mathrm{J} 1$ & $6+2$ & \multirow{6}{*}{$>_{J 3}$} & \multirow{6}{*}{$6+3+2+4+6$} \\
\hline & $\mathrm{T} 2+\mathrm{J} 1$ & $3+2$ & & \\
\hline \multirow{4}{*}{ Removal-to-Shore } & $\mathrm{T} 1+\mathrm{J} 2$ & $6+4$ & & \\
\hline & $\mathrm{T} 1+\mathrm{J} 3$ & $6+6$ & & \\
\hline & $\mathrm{T} 2+\mathrm{J} 2$ & $3+4$ & & \\
\hline & $\mathrm{T} 2+\mathrm{J} 3$ & $3+6$ & & \\
\hline \multicolumn{2}{|c|}{ Total time } & 51 & & 21 \\
\hline
\end{tabular}

with ifcbuildingelementproxy, which is used to represent entities that have not been defined in IFC. Surface model that consists of points in $3 \mathrm{D}$ environment is usually used by ifcbuildingelementproxy to represent the undefined object. The lack of BIM applications of the oil and gas industry, especially offshore oil and gas platforms, may be one possible reason. Therefore, if the oil and gas industry wants to benefit from BIM technology, necessary efforts should be conducted on IFC extension to the oil and gas industry or new data models need to be developed in the future.

\section{Acknowledgements}

The authors would like to thank the partial support for this research that was provided by Australian Research Council Linkage Project (ARC LP130100451).

\section{Funding}

This study is partially supported by Australian Research Council Linkage Project (ARC LP130100451).

Recipient: Xiangyu Wang.

\section{Authors' contributions}

JCPC and YT: They proposed the research idea of applying 4D/5D BIM to visualize offshore oil and gas platform (OOGP) decommissioning methodology options. YT did most of the work, including OOGP BIM model modification, 4D and 5D BIM models creation, scenarios comparison, and paper writing. JCPC, as YT's supervisor, provide direct academic guidance for this research, including research contents discussion, helping to organize the paper structure, and paper proofreading. YS, XL and XW: As the collaborators of this research, they provide the original OOGP models and some OOGP decommissioning data such as OOGP decommissioning activities as well as their duration. Besides, they also provide practical suggestions for this research by group discussions. All authors read and approved the final manuscript.

\section{Competing interests}

The authors declare that they have no competing interests.

\section{Publisher's Note}

Springer Nature remains neutral with regard to jurisdictional claims in published maps and institutional affiliations.

\section{Author details}

${ }^{1}$ Department of Civil and Environmental Engineering, The Hong Kong University of Science and Technology, Hong Kong, China. ${ }^{2}$ Australasian Joint Research Centre for BIM, School of Built Environment, Curtin University, Perth, Australia.

Received: 5 October 2016 Accepted: 30 June 2017

Published online: 14 July 2017

\section{References}

Bernstein, B. B. (2015). Evaluating alternatives for decommissioning California's offshore oil and gas platforms. Integrated environmental assessment and management, 11(4), 537-541.

Cheng, J. C. P., Lu, Q., \& Deng, Y. (2016). Analytical review and evaluation of civil information modeling. Automation in Construction, 67, 31-47. doi: http://dx. doi.org/10.1016/j.autcon.2016.02.006

Decision, O. S. P. A. R. (1998). 98/3 on the Disposal of Disused Offshore Installations. In Ministerial Meeting of the OSPAR Commission, OSPAR Convention for the protection of the marine environment of the North-East Atlantic, London, UK.

Han, K. K., \& Golparvar-Fard, M. (2015). Appearance-based material classification for monitoring of operation-level construction progress using 4D BIM and site photologs. Automation in Construction, 53, 44-57. doi: http://dx.doi.org/ 10.1016/j.autcon.2015.02.007

Henrion, M., Bernstein, B., \& Swamy, S. (2015). A multi-attribute decision analysis for decommissioning offshore oil and gas platforms. Integrated Environmental Assessment and Management, 11(4), 594-609. doi:10.1002/ieam.1693

Hu, Z., Zhang, J., \& Deng, Z. (2008). Construction process simulation and safety analysis based on building information model and 4D technology. Tsinghua Science \& Technology, 13, Supplement 1, 266-272. doi: http://dx.doi.org/10. 1016/S1007-0214(08)70160-3

Kacprzyk, Z., \& Kępa, T. (2014). Building information Modelling - 4D Modelling technology on the example of the reconstruction stairwell. Procedia Engineering, 91, 226-231. doi: http://dx.doi.org/10.1016/j.proeng.2014.12.051

Kim, C., Son, H., \& Kim, C. (2013). Automated construction progress measurement using a $4 \mathrm{D}$ building information model and $3 \mathrm{D}$ data. Automation in Construction, 31, 75-82. doi: http://dx.doi.org/10.1016/j.autcon.2012.11.041

Lu, Q., Won, J., \& Cheng, J. C. P. (2016). A financial decision making framework for construction projects based on 5D building information modeling (BIM). International Journal of Project Management, 34(1), 3-21. doi: http://dx.doi. org/10.1016/j.ijproman.2015.09.004

Mitchell, D. (2012). 5D BIM: Creating cost certainty and better buildings. Paper presented at the 2012 RICS Cobra Conference.

Moon, H., Dawood, N., \& Kang, L. (2014). Development of workspace conflict visualization system using 4D object of work schedule. Advanced Engineering Informatics, 28(1), 50-65. doi: http://dx.doi.org/10.1016/j.aei.2013.12.001 
Scheer, S., Mendes Jr, R., Campestrini, T., \& Garrido, M. (2014). On site BIM model use to integrate $4 \mathrm{D} / 5 \mathrm{D}$ activities and construction works: A case study on a Brazilian low income house enterprise.

Statista. (2015). Number of offshore rigs worlwide as of 2015, by region. Available on: https://www.statista.com/statistics/279100/number-of-offshore-rigsworldwide-by-region/, Accessed on 5 Jan 2017.

Synchro Pro [Computer software]. (2016). Retrieved from: https://www.synchroltd.com/ Accessed 1 Oct 2016.

Tan, Y., Song, Y., Liu, X., Wang, X., \& Cheng, J. C. P. (2017). A BIM-based framework for lift planning in topsides disassembly of offshore oil and gas platforms. Automation in construction. doi: http://dx.doi.org/10.1016/j.autcon.2017.02.008

UK Oil \& Gas Economic Report. (2013). Available at: http://oilandgasuk.co.uk/wpcontent/uploads/2015/05/EC038.pdf Accessed 11 Sept 2016

Zawawi, N. A. W. A., Liew, M., \& Na, K. (2012). Decommissioning of offshore platform: A sustainable framework. Paper presented at the Humanities, Science and Engineering (CHUSER), 2012 IEEE Colloquium on.

Zhou, Y., Ding, L. Y., \& Chen, L. J. (2013). Application of 4D visualization technology for safety management in metro construction. Automation in Construction, 34, 25-36. doi: http://dx.doi.org/10.1016/j.autcon.2012.10.011

\section{Submit your manuscript to a SpringerOpen ${ }^{\bullet}$ journal and benefit from:}

- Convenient online submission

- Rigorous peer review

- Open access: articles freely available online

- High visibility within the field

- Retaining the copyright to your article

Submit your next manuscript at $\boldsymbol{s p r i n g e r o p e n . c o m ~}$ 